\title{
The mitochondrial genome of the stingless bee Melipona bicolor (Hymenoptera, Apidae, Meliponini): Sequence, gene organization and a unique tRNA translocation event conserved across the tribe Meliponini
}

\author{
Daniela Silvestre $^{1}$, Mark Dowton ${ }^{2}$ and Maria Cristina Arias ${ }^{1}$ \\ ${ }^{1}$ Departamento de Genética e Biologia Evolutiva, Instituto de Biociências, Universidade de São Paulo, \\ São Paulo, SP, Brazil. \\ ${ }^{2}$ Institute of Biomolecular Sciences and Conservation Biology, Department of Biology, \\ The University of Wollongong, New South Wales, Australia.
}

\begin{abstract}
At present a complete mtDNA sequence has been reported for only two hymenopterans, the Old World honey bee, Apis mellifera and the sawfly Perga condei. Among the bee group, the tribe Meliponini (stingless bees) has some distinction due to its Pantropical distribution, great number of species and large importance as main pollinators in several ecosystems, including the Brazilian rain forest. However few molecular studies have been conducted on this group of bees and few sequence data from mitochondrial genomes have been described. In this project, we PCR amplified and sequenced $78 \%$ of the mitochondrial genome of the stingless bee Melipona bicolor (Apidae, Meliponini). The sequenced region contains all of the 13 mitochondrial protein-coding genes, 18 of 22 tRNA genes, and both rRNA genes (one of them was partially sequenced). We also report the genome organization (gene content and order), gene translation, genetic code, and other molecular features, such as base frequencies, codon usage, gene initiation and termination. We compare these characteristics of $M$. bicolor to those of the mitochondrial genome of $A$. mellifera and other insects. A highly biased $\mathrm{A}+\mathrm{T}$ content is a typical characteristic of the $A$. mellifera mitochondrial genome and it was even more extreme in that of $M$. bicolor. Length and compositional differences between $M$. bicolor and $A$. mellifera genes were detected and the gene order was compared. Eleven tRNA gene translocations were observed between these two species. This latter finding was surprising, considering the taxonomic proximity of these two bee tribes. The tRNA ${ }^{\text {Lys }}$ gene translocation was investigated within Meliponini and showed high conservation across the Pantropical range of the tribe.
\end{abstract}

Key words: Melipona bicolor, Meliponini, social insects, mitochondrial genome, gene rearrangements.

Received: September 27, 2007; Accepted: February 12, 2008.

\section{Introduction}

In recent years a number of mitochondrial genomes have been completely sequenced, contributing to the knowledge of molecular features related to function and evolution of this peculiar genome (Boore, 1999). Its gene content is typically rather conserved in Metazoa (Boore et al., 1995), with notable exceptions described in nematodes (Okimoto et al., 1992), molluscs (Hoffmann et al., 1992) and cnidarians (Beagley et al., 1998). In general, mitochondrial DNA (mtDNA) contains genes for two ribosomal subunits (12S and 16S), 22 tRNA, and 13 proteins (three subunits of cytochrome c oxidase, cytochrome B, subunits

Send correspondence to Maria Cristina Arias. Departamento de Genética e Biologia Evolutiva, Instituto de Biociências, Universidade de São Paulo, Rua do Matão 277, 05508-900 São Paulo, SP, Brazil. E-mail: mcarias@ib.usp.br.
6 and 8 of ATP F0 synthase, and seven subunits of NADH dehydrogenase). There is also a non-coding $\mathrm{A}+\mathrm{T}$ rich region that contains signaling elements for regulation of replication and transcription (Wolstenholme, 1992). Animal mitochondrial genome size is usually about $16 \mathrm{~kb}$ long, with few exceptions (Brown, 1985). Gene rearrangements within the mtDNA, formerly considered rare, have been described for a number of taxa, including bees (Mindell et al., 1998; Dowton and Campbell, 2001; Shao et al., 2003; Silvestre et al., 2002; Silvestre and Arias, 2006).

One hundred sixteen complete arthropod mtDNA sequences, including 61 insect species, have been deposited in GenBank. In the described insect mtDNA genomes, A+T content is very high. Currently, complete mitochondrial genomes have been sequenced for just two hymenopteran species: the sawfly Perga condei (Castro and Dowton, 2005 ) and the honeybee Apis mellifera (Crozier and Cro- 
zier, 1993). The honeybee mtDNA presents the highest $\mathrm{A}+\mathrm{T}$ bias $(84.9 \%)$ known for insects. According to Crozier and Crozier (1993) the $\mathrm{A}+\mathrm{T}$ bias is probably maintained due to a greater number of transversions over transitions.

Among bees, the tribe Meliponini, known as stingless bees, has gained some attention. The tribe has a wide geographic distribution, inhabits all tropical areas of the World (Michener, 2000), and includes the main pollinators in several neotropical ecosystems (Kerr et al., 1996). In addition to their ecological importance, some species produce honey, pollen, wax and propolis that are commercially exploited (Nogueira-Neto, 1997). The species Melipona bicolor presents a very unique behavioral characteristic, polygyny, where several laying queens may cohabitate the nest for considerable time (Velthuis et al., 2006). This species is distributed in the southern and southeastern Brazil, in the Atlantic rain forest. Nonetheless as this ecosystem has been severely reduced in size by human activity and only $7 \%$ of the original area remains, M. bicolor and other bees are considered endangered.

In previous studies we have characterized the mitochondrial genomes of several meliponine species through RFLP analysis (Francisco et al., 2001; Weinlich et al., 2004; Brito and Arias, 2005). Evidences of size difference, in comparison to those expected for Apis mellifera, were obtained for some mitochondrial regions after PCR amplification. Those data were interpreted as indirect evidence of gene order or content changes. Later these size differences, relative to A. mellifera, were confirmed by sequencing (Silvestre et al., 2002; Silvestre and Arias, 2006), and all involved tRNA gene rearrangements. Eleven tRNA translocations were mapped between A. mellifera and M. bicolor (Arias et al., 2006), so far the highest translocation number verified between species belonging to the same taxonomic subfamily.

Mitochondrial gene order has been considered a molecular class very promising for phylogenetic studies, especially among major taxonomic groups (Boore, 1999). tRNA rearrangements are highly reliable as evolutionary markers, neutral and less prone to homoplasy (Boore and Brown, 1998). We previously sequenced a portion of the mitochondrial genome of $M$. bicolor, and reported that there were 11 tRNA gene rearrangements when this genome was compared with that of Apis mellifera (Silvestre et al., 2002; Silvestre and Arias, 2006). However, in that report we did not extensively characterize the M.bicolor mitochondrial genome, focusing our observations on genome organization. In the present study, we present a thorough characterization of the $M$. bicolor mitochondrial genome, with respect to codon usage, base frequencies, gene initiation and termination, and tRNA structure. In addition, we examine the evolutionary origin of one of the tRNA gene rearrangements identified in the previous study, the translocation of the tRNA ${ }^{\text {Lys }}$ gene. We survey a broad range of Meliponini to more accurately determine the evolutionary origin of this translocation.

\section{Material and Methods}

\section{mtDNA sequence analysis}

Individuals of $M$. bicolor were collected from a single monogynic colony maintained at the Laboratório de Abelhas, Departamento de Ecologia, IB-USP, São Paulo. Total genomic DNA was extracted using the TNEprotocol (Sheppard and McPheron, 1991). The experimental approach to obtain the whole mtDNA molecule consisted of the amplification of small and overlapped fragments. Thus aliquots of TNE extraction were used as template for PCR reactions, with Taq DNA polymerase (Invitrogen). We initially used the following conditions: denaturation at $94{ }^{\circ} \mathrm{C} / 5 \mathrm{~min}$, followed by 35 cycles of $94{ }^{\circ} \mathrm{C} / 60 \mathrm{~s}, 42^{\circ} \mathrm{C} / 80 \mathrm{~s}$ and $64^{\circ} \mathrm{C} / 120 \mathrm{~s}$. An additional final extension step of $64^{\circ} \mathrm{C}$ for $10 \mathrm{~min}$ was performed. The annealing temperature was optimized when necessary. The primers were derived from A. mellifera (Hall and Smith, 1991; Arias et al., 2008), M. bicolor (designed in our laboratory), and other organisms (Simon et al., 1994) (Table 1).

The PCR products were cloned into pGEM T-Easy Vector (Promega). At least two clones of each region were sequenced on both directions using Thermo Sequenase Dye Terminator (Amersham Life Science) or Big Dye Terminator (Applied Biosystems). Samples were analyzed on ABIPRISM 310 and 3100 automated sequencers (Applied Biosystems).

Electropherograms were checked by eye on TraceViewer 2.0.1, and the sequences were assembled manually through GeneRunner 3.00 program (Hastings Software). Automated alignments were obtained using DAMBE (Xia, 2000), employing the CLUSTALW algorithm. Codon usage was analyzed with the software CODONTREE. BLAST searches at National Center for Biotechnology Information (NCBI) were used to verify the similarity between our sequences and those from other insect mitochondrial genomes. Transfer RNA genes were identified and the secondary structures were inferred by the software tRNA-Scan (Lowe and Eddy, 1997).

A single sequence of $14,422 \mathrm{bp}$ was assembled and deposited at GenBank database under the accession number AF466146, which has also a Genome accession number, NC_004529.

\section{KD tRNA cluster analysis}

Fourteen Meliponini species (Table 2) were selected for the KD tRNA cluster sequencing. The species analyzed, collected in four continents, may be considered representative of the Pantropical geographic distribution of the tribe. The KD region was amplified using the pair of primers Cox 2/ Atp8 and the PCR conditions described in Castro et al. (2002). The computational analyses were as described above. 
Table 1 - Set of primers utilized on PCR amplification of M. bicolor mtDNA: positioning (relative to mitochondrial genes), strand, sequences and references.

\begin{tabular}{|c|c|c|c|c|}
\hline Primer & Position (gene) & Strand & Sequence $\left(5^{\prime}-3^{\prime}\right)$ & Reference \\
\hline *11781F & CytB & $<$ & TTTAAAATTATCTGGATCTC & (this work) \\
\hline$* 16 \mathrm{SF}$ & $16 \mathrm{~S}$ & $<$ & CACCTGTTTATCAAAAACATGTCC & Hall and Smith, 1991 \\
\hline *16SR & $16 \mathrm{~S}$ & $>$ & CGTCGATTTGAACTCAAATCATG & Hall and Smith, 1991 \\
\hline *8321R & ND5 & $>$ & TTATATATCTAATTCTAT & (this work) \\
\hline$* 8467 \mathrm{~F}$ & ND5 & $<$ & GGAATTTTTTTTTGAATGAAA & (this work) \\
\hline *C1-J-1718 & COI & $>$ & GGATCACCTGATATAGCATTCCC & Simon et al., 1994 \\
\hline *C2-J-3696 & COII & $>$ & GAAATTTGTGGAGCAAATCATAG & Simon et al., 1994 \\
\hline${ }^{*} \mathrm{C} 2-\mathrm{N}-3661$ & COII & $<$ & CCACAAATTTCTGAACATTGACCA & Simon et al., 1994 \\
\hline${ }^{*} \mathrm{C} 3-\mathrm{N}-5460$ & COIII & $<$ & TCAACAAAGTGTCAGTATCA & Simon et al., 1994 \\
\hline *CB-J-10933 & CytB & $>$ & TATGTACTACCATGAGGACAAATATC & Simon et al., 1994 \\
\hline$* \mathrm{~N} 1-\mathrm{J}-12585$ & ND1 & $>$ & GGTCCCTTACGAATTTGAATATATCCT & Simon et al., 1994 \\
\hline *N1-N-12595 & ND1 & $<$ & GTAGCATTTTTAACTTTATTAGAACG & Simon et al., 1994 \\
\hline$* \mathrm{ND} 4 \mathrm{~F}$ & ND4L & $<$ & ATAAATTATGAACTTGGTCATCA & (this work) \\
\hline *Mbi 18 & ND3 & $<$ & GAACTATCAATTTGATATTG & (this work) \\
\hline *Mbi 29 & ND4 & $>$ & CGAAATTCACCATAACCTC & (this work) \\
\hline *SR-N-14588 & $12 \mathrm{~S}$ & $<$ & AAACTAGGATTAGATACCCTATTAT & Simon et al., 1994 \\
\hline *TM-J-206 & RNAt $^{\text {Met }}$ & $>$ & GCTAAATAGCTAACAGGTTCAT & Simon et al., 1994 \\
\hline $5612 \mathrm{R}$ & COIII & $>$ & GAAATTAATATAACATGACCACC & Arias unpublished data \\
\hline AMB 1 & RNAt $^{\text {Ile }}$ & $>$ & TGATAAAAGAAATATTTTGA & Arias unpublished data \\
\hline AMB 3 & $\mathrm{RNAt}^{\mathrm{Trp}}$ & $>$ & TTTAAAAACTATTAATCTTC & Arias unpublished data \\
\hline AMB 4 & COI & $<$ & GAAAGTTAGATTTACTCC & Arias unpublished data \\
\hline L2Eco & ND2 & $<$ & TTTTAGAATTCTGAAACTAATATATAAATTG & (this work) \\
\hline Mel 2 & ATPase 8 & $<$ & TGGAAAAATAATAATTG & (this work) \\
\hline MtD 35Eco & $12 \mathrm{~S}$ & $>$ & ATTCCGAATTCAAACTGAACGGGCAATTTGT & (this work) \\
\hline Mbi 02 & $\mathrm{COI}$ & $>$ & GATCCAATAGGAGGAGGAG & (this work) \\
\hline Mbi 03 & COII & $<$ & GGTATTAACGTTCAAATAATTTC & (this work) \\
\hline Mbi 04 & CytB & $>$ & CAATTCCAAATAAATTAGGAGG & (this work) \\
\hline Mbi 05a & ND1 & $<$ & TTTAATCGAGTTCCATTTG & (this work) \\
\hline Mbi 06 & $16 \mathrm{~S}$ & $>$ & CAATTGATTATGCTACCTTTG & (this work) \\
\hline Mbi 09 & COI & $>$ & GATTTCCATTAATTTCAGG & (this work) \\
\hline Mbi 10 & ATPase 8 & $>$ & TTGACTTATTCCTTCATG & (this work) \\
\hline Mbi 11 & COIII & $<$ & CGGATAATATCTCGAAATC & (this work) \\
\hline Mbi 12 & ND1 & $>$ & CTAATTCTGATTCTCCCTC & (this work) \\
\hline Mbi 13 & $16 \mathrm{~S}$ & $>$ & CCCTGATACAAAAGGTAC & (this work) \\
\hline Mbi 14 & COII & $>$ & TAATATGGCAGATTAAGTGC & (this work) \\
\hline Mbi 16 & COIII & $>$ & TAAAAAATAGTCCCCGACC & (this work) \\
\hline Mbi 19 & ND3 & $<$ & TGGGATTGAATCCATATTC & (this work) \\
\hline Mbi 21 & COII & $>$ & CTATTAAAACAATTGGTCATC & (this work) \\
\hline Mbi 22 & $\mathrm{COI}$ & $<$ & GATGTAAAATATGCTCGTG & (this work) \\
\hline Mbi 23 & ND5 & $<$ & TCGATTCGGAGATAGAGG & (this work) \\
\hline Mbi 24 & COIII & $>$ & GATTTCGAGATATTATCCG & (this work) \\
\hline Mbi 25 & $\mathrm{RNAt}^{\mathrm{Arg}}$ & $>$ & GATTTATGTTTAAGTCGA & (this work) \\
\hline Mbi 27 & $16 \mathrm{~S}$ & $<$ & GTTTAAAGTAATGTAAATG & (this work) \\
\hline Mbi 30 & ND1 & $<$ & TCGAGTTCCATTTGATTT & (this work) \\
\hline Mbi 31 & ND5 & $>$ & TCGAGTTCCATTTGATTT & (this work) \\
\hline Mbi 32 & CytB & $<$ & AATGCAGTTGCTATTGATA & (this work) \\
\hline Mbi 33 & ND4L & $>$ & TTTTGATGGACCCAAATTC & (this work) \\
\hline Mbi 34 & ND5 & $<$ & TCTACATTAAGACAATTAGG & (this work) \\
\hline Mbi 35 & ND5 & $>$ & CATTATAAAACCTAATTGTC & (this work) \\
\hline Mbi 36 & ND4 & $>$ & TTCCATGTTCAACAAATCT & (this work) \\
\hline Mbi 37 & ND4 & $<$ & TATATTTAATTCATGGTTG & (this work) \\
\hline Mbi 38 & RNAt $^{\text {Pro }}$ & $>$ & TTAAATTATCTACAATCCC & (this work) \\
\hline Mbi 39 & CytB & $<$ & TATTGATAGGTGTAGGAAG & (this work) \\
\hline Mbi 40 & ND2 & $>$ & CTATATCATCTATTTCATC & (this work) \\
\hline Mbi 41 & COI & $<$ & CATATAAAGATTAAAATTC & (this work) \\
\hline Mbi 43 & ND2 & $>$ & TAAAACAATTTATCATATTTTG & (this work) \\
\hline Mbi 44 & ND2 & $<$ & TAAATAATAATTTTTATATG & (this work) \\
\hline Mbi 47 & ND6 & $<$ & TGAAAATAAAATAATTTGG & (this work) \\
\hline TPheF & RNAt $^{\text {Phe }}$ & $<$ & GCGTAATATTGAAAATATTAATGA & (this work) \\
\hline
\end{tabular}

*Primers initially used to amplify longer amplicons, covering most of the genome. These regions were re-amplified in smaller fragments to continue the sequencing process. 
Table 2 - Meliponini species and countries of origin.

\begin{tabular}{lc}
\hline Species & Country \\
\hline Austroplebeia australis & Australia \\
Austroplebeia symei & Australia \\
Trigona carbonaria & Australia \\
Trigona hockingsi & Australia \\
Lestrimellita limao & Brazil \\
Plebeia remota & Brazil \\
Scaptotrigona xanthotricha & Brazil \\
Schwarziana quadripunctata & Brazil \\
Tetragonisca angustula & Brazil \\
Dactylurina sp & Ghana \\
Liotrigona sp & Ghana \\
Heterotrigona iridipennis & India \\
Trigona doipaensis & Thailand \\
Trigona flavibasis & Thailand \\
\hline
\end{tabular}

\section{Results and Discussion}

\section{General features of the genome and gene content}

The size of the M. bicolor mtDNA had been previously estimated to be 18,500 bp by RFLP analyses (Weinlich et al., 2004). However, this total size could not be fully confirmed by sequencing, we were unable to clone the 4,100 bp fragment containing the control region and its adjacent region. We analyzed a continuous fragment of $14,422 \mathrm{bp}$, or about $78 \%$ of the estimated size. This fragment contains the 13 protein-coding genes, 18 of 22 tRNA genes and the two rRNA genes (complete sequence was obtained for the large subunit - 16S, and partial sequence for the small subunit - 12S) (Figure 1). We detected five overlapping regions between genes, three of them including genes that were on the same strand (Table 3). In total, $30 \mathrm{bp}$ were involved.

Seventeen non-coding regions were detected, with sizes ranging from one to $173 \mathrm{bp}$, totaling $486 \mathrm{bp}$ (Table 4). Considering the same portion of $A$. mellifera mtDNA, excluding the hypervariable $\mathrm{COI}-\mathrm{COII}$ intergenic region and the control region, the number of non-coding nucleotides is
Table 3 - Overlapping regions between mitochondrial genes of $M$. bicolor: involved genes, overlap size (bp) and coding strand.

\begin{tabular}{lcc}
\hline Genes & Size $(\mathrm{bp})$ & Strand \\
\hline ATP8/ATP6 & 10 & $+/+$ \\
tRNA $^{\text {Glu }} /$ tRNA $^{\text {Phe }}$ & 6 & $+/-$ \\
tRNA $^{\text {His }} / \mathrm{ND} 4$ & 6 & $-/-$ \\
ND1/tRNA $^{\text {Leu(L1) }}$ & 6 & $-/-$ \\
tRNA $^{\text {Ser(S2) } / N D 1 ~}$ & 2 & $+/-$ \\
\hline Total & 30 & \\
\hline
\end{tabular}

Table 4 - Non-coding regions between mitochondrial genes of M. bicolor: flanking genes and size (bp).

\begin{tabular}{|c|c|}
\hline Genes & Size (bp) \\
\hline $\mathrm{tRNA}^{\mathrm{Met}} / \mathrm{ND} 2$ & 173 \\
\hline ND6/CytB & 94 \\
\hline $\mathrm{tRNA}^{\mathrm{Asn}} / \mathrm{tRNA}^{\text {Glu }}$ & 58 \\
\hline $\mathrm{tRNA}^{\mathrm{Tyr}} / \mathrm{COI}$ & 58 \\
\hline tRNA ${ }^{\text {Pro }} / \mathrm{ND6}$ & 23 \\
\hline ATP6/COIII & 15 \\
\hline COII/tRNA ${ }^{\text {Asp }}$ & 12 \\
\hline ND4/ND4L & 10 \\
\hline COIII/tRNA ${ }^{\text {Gly }}$ & 9 \\
\hline CytB/tRNA ${ }^{\text {Ser(S2) }}$ & 9 \\
\hline $\mathrm{tRNA}^{\mathrm{Lys}} / \mathrm{tRNA}^{\mathrm{Met}}$ & 6 \\
\hline ND2/tRNA ${ }^{\text {Trp }}$ & 5 \\
\hline $\mathrm{tRNA}^{\mathrm{Arg}} / \mathrm{tRNA}^{\mathrm{Asn}}$ & 5 \\
\hline ND4L/tRNA ${ }^{\text {Thr }}$ & 4 \\
\hline ND3/tRNA ${ }^{\text {Arg }}$ & 3 \\
\hline tRNA ${ }^{\text {Phe }} / \mathrm{ND} 5$ & 1 \\
\hline $\mathrm{tRNA}^{\mathrm{Trp}} / \mathrm{tRNA}^{\mathrm{Tyr}}$ & 1 \\
\hline Total & 486 \\
\hline
\end{tabular}

greater, 618 bp (Crozier and Crozier, 1993). Thus, comparing the sequenced portion of $M$. bicolor genome with the respective genome portion of A. mellifera, we verified that $M$. bicolor presents a more compact arrangement.

The COI-COII intergenic region known to occur in $A$. mellifera was absent in M. bicolor. Moreover, indirect PCR evidence indicated that the COI-COII region is absent in at least 16 other Meliponini species (Arias et al., 2006). This intergenic region has been extensively studied in $A$.

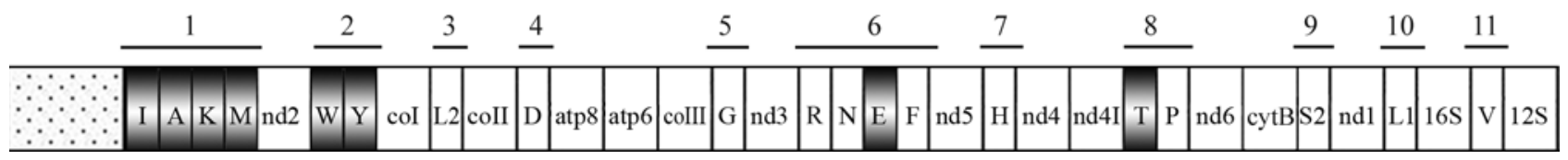

Figure 1 - Linearized mitochondrial genomic map of M. bicolor (not in scale). Dots indicate a region not sequenced. Dark boxes indicate tRNA that underwent translocation in comparison to Apis mellifera mitochondrial gene order. Numbers above the map indicate the tRNA clusters. I - tRNA ${ }^{\text {Ile }}$; A $\mathrm{tRNA}^{\mathrm{Ala}} ; \mathrm{K}$ - tRNA ${ }^{\text {Lys }}$; M - tRNA ${ }^{\mathrm{Met}}$; nd2 - NADH dehidrogenase subunit 2; W - tRNA ${ }^{\text {Trp }}$ Y Y - tRNA ${ }^{\text {Tyr }}$; coI - cytochrome c oxidase subunit I; L2 tRNA $^{\text {Leu }}$ (UUR); coII - cytochrome c oxidase subunit II; D - tRNA Asp; atp8 - ATP synthase subunit 8; atp6 - ATP synthase subunit 6; coIII - cytochrome c oxidase subunit III; G - tRNA ${ }^{\text {Gly }}$; nd3 - NADH dehydrogenase subunit 3; R - tRNA ${ }^{\text {Arg }}$; N - tRNA ${ }^{\text {Asn }}$; E - tRNA ${ }^{\text {Glu }}$; F - tRNA ${ }^{\text {Phe }}$; nd5 - NADH dehydrogenase subunit 5; H - tRNA ${ }^{\text {His }}$; nd4 - NADH dehydrogenase subunit 4; nd4L - NADH dehydrogenase subunit 4 (light chain); T - tRNA ${ }^{\text {Thr }}$; P $\mathrm{tRNA}^{\mathrm{Pro}}$; nd6 - NADH dehydrogenase subunit 6; cytB - cytochrome B; S2 - tRNA ${ }^{\mathrm{Ser}}(\mathrm{UCN})$; nd1 - NADH dehydrogenase subunit 1; L1 - tRNA ${ }^{\mathrm{Leu}}(\mathrm{CUN})$; $16 \mathrm{~S}$ - rRNA 16S; V - tRNA ${ }^{\text {Val }}$; $12 \mathrm{~S}$ - rRNA $12 \mathrm{~S}$. 
mellifera, and size polymorphism has been reported (from 200 to $650 \mathrm{bp}$ ) among subspecies (Garnery et al., 1992, 1995; Franck et al., 1998). It has also been cited as a possible second origin of mtDNA replication and transcription (Cornuet et al., 1991). Our data clearly suggest that this region and possible function is not a shared feature between A. mellifera and Meliponini, in a broader sense.

The longest intergenic region found in $M$. bicolor consisted of $173 \mathrm{bp}$ and was located between the tRNA ${ }^{\mathrm{Met}}$ and ND2 genes. Concerning the sequence similarities between $M$. bicolor and $A$. mellifera, we observed a $46 \mathrm{bp}$ segment within this region that was highly similar $(84 \%)$ to the non-coding region between COIII and tRNA ${ }^{\text {Gly }}$ of $A$. mellifera.

The second longest non-coding region of $M$. bicolor mtDNA was located between the ND6 and CytB genes and was $94 \mathrm{bp}$ in length. In $A$. mellifera this non-coding region is $60 \mathrm{bp}$ long. The sequence similarity between these was $61 \%$. The other intergenic regions found in M. bicolor were also analyzed, but were too small and showed no significant similarities with any region of the mtDNA of $A$. mellifera or other organisms.

\section{Base composition - $\mathrm{A}+\mathrm{T}$ bias}

The adenine+thymine bias was very high in $M$. bicolor mtDNA $(86.7 \%)$, as has been described in $A$. mellifera (84.9\% Crozier and Crozier, 1993). This latter species, as a member of Hymenoptera, has been cited to be the most AT biased insect mitochondrial genome sequenced (Simon et $a l ., 1994)$. One hypothesis that attempts to explain this bias is that the DNA polymerase could use those bases in a more efficient way during mtDNA replication (Clary and Wolstenholme, 1985). The lower energetic cost to break the A-T links during mtDNA replication and transcription would generate AT bias on organisms that rely on mitochondrial efficiency to keep a high metabolic rate (Xia, 1996). Studies of additional Apidae genomes may indicate whether (and when) this character was fixed by selection for high metabolism in the evolutionary history of this group.

\section{Protein-coding genes}

The mitochondrial protein-coding genes were analyzed and nucleotide composition, codon usage and size were compared with $A$. mellifera. The initiation codons in $M$. bicolor protein-coding genes were seven ATT (for isoleucine), four ATA, and two ATG (both for methionine). Although the insect mitochondrial genetic code predicts isoleucine for the first codon, it is generally assumed that a special feature on translation changes all mitochondrial initiation codons to methionine on the final amino acid sequence (Wolstenholme, 1992). As in A. mellifera, there was no anomalous initiation codon (like D. yakuba ATAA; Clary and Wolstenholme, 1985). All M. bicolor stop codons are TAA, the standard for the mitochondrial genetic code (Wolstenholme, 1992). There were no incomplete codons (T or TA), as found in two genes of $A$. mellifera and four of D. yakuba (Crozier and Crozier, 1993).

The standard insect mitochondrial genetic code was used to analyze $M$. bicolor mtDNA successfully, since it yielded no stop codons within the gene sequences. The total number of codons (excepting start and stop codons) was 3,643, while the $A$. mellifera genome has 3,686. The codon usage of all $M$. bicolor protein-coding genes was compared with $A$. mellifera (Table 5). It is possible to observe that there is a preferred codon for each amino acid, generally ending with A or T. Interestingly, these codons are not always the complement to their anticodons, particularly when these latter begin with $\mathrm{C}$ or $\mathrm{G}$, a feature that is common in insects (Foster et al., 1997). In A. mellifera, there are seven codons that are not used at all, and in $M$. bicolor there are even more, 12 non-used codons, all ending with $\mathrm{C}$ or $\mathrm{G}$.

The AT bias in codon usage can be expressed in terms of the ratio of " $\mathrm{G}+\mathrm{C}$ " (Pro, Ala, Arg and Gly) to " $\mathrm{A}+\mathrm{T}$ " rich codons (Phe, Ile, Met, Tyr, Asn and Lys) (Crozier and Crozier, 1993). That ratio is 0.43 for D. yakuba, 0.18 for $A$. mellifera and 0.14 for $M$. bicolor, confirming the extreme AT bias of bee mtDNA. Foster et al. (1997) developed a graphical and statistical representation for the nucleotide usage on first and second codon positions, called square plots, to analyze AT bias on mitochondrial protein-coding genes. Those graphics do not use the third position because it is too variable and generally does not reflect the amino acid composition. Figure 2 represents the square plot of $M$. bicolor. The AT bias is evident, as most codons are in the first quadrant (two positions occupied by $\mathrm{A}$ or $\mathrm{T}$ ).

Table 6 summarizes the results obtained for all the protein-coding genes of $M$. bicolor, and the comparisons with $A$. mellifera. One of the most intriguing features noticed is the size difference for some genes between the two bees. The cytB gene presents the most extreme example, being 102 bp shorter in $M$. bicolor, such difference is concentrated at the amino terminal portion of the cytB protein, therefore the reading frame starts 34 codons downstream in reference to $A$. mellifera. Moreover the former species presents a non-coding region of $94 \mathrm{bp}$ preceding the cytB gene, with 13 possible initiation codons (nine ATT and four ATA). However none of these give rise to a continuous reading frame. Base substitution or even deletion may explain the absence and presence of the initiation codon at different positions than expected. This difference becomes more striking if one considers that cytB is one of the most conserved mitochondrial gene (Simon et al., 1994).

\section{Ribosomal RNA genes}

The precise size of ribosomal RNA transcripts are normally difficult to infer from the DNA sequence by itself, so it is assumed that they end on the boundaries of the flanking genes (Boore, 2001). The M. bicolor large subunit of ribosomal RNA gene (lrRNA or 16S) was completely sequenced. It has $1,354 \mathrm{bp}, 17 \mathrm{bp}$ smaller than the $A$. 
Table 5 - Mitochondrial codons and the absolute number of occurrences on the set of protein-coding genes of M. bicolor (Mbi) and A. mellifera (Ame). The anticodon of the corresponding tRNA are presented in parenthesis and ? indicates the anticodons not determined for M. bicolor.

\begin{tabular}{|c|c|c|c|c|c|c|c|}
\hline $\begin{array}{l}\text { Amino } \\
\text { acid }\end{array}$ & Codon & Mbi & Ame & $\begin{array}{l}\text { Amino } \\
\text { acid }\end{array}$ & Codon & Mbi & Ame \\
\hline \multirow{4}{*}{$\begin{array}{l}\text { Ser } \\
(?)\end{array}$} & AGA & 72 & 81 & \multirow{4}{*}{$\begin{array}{l}\text { Gly } \\
\text { (ucc) }\end{array}$} & GGA & 82 & 85 \\
\hline & AGC & 0 & 2 & & GGC & 0 & 0 \\
\hline & AGG & 6 & 2 & & GGG & 1 & 3 \\
\hline & AGT & 22 & 18 & & GGT & 29 & 47 \\
\hline \multirow{4}{*}{$\begin{array}{l}\text { Ser } \\
\text { (uga) }\end{array}$} & TCA & 143 & 166 & \multirow{4}{*}{$\begin{array}{l}\text { Thr } \\
\text { (ugu) }\end{array}$} & ACA & 45 & 72 \\
\hline & TCC & 2 & 11 & & ACC & 0 & 5 \\
\hline & TCG & 0 & 1 & & ACG & 0 & 1 \\
\hline & TCT & 67 & 53 & & ACT & 37 & 53 \\
\hline \multirow{5}{*}{$\begin{array}{l}\text { Leu } \\
\text { (uag) }\end{array}$} & CTA & 12 & 36 & \multirow{3}{*}{$\begin{array}{l}\text { Asp } \\
\text { (guc) }\end{array}$} & GAC & 1 & 5 \\
\hline & CTC & 1 & 1 & & GAT & 47 & 52 \\
\hline & CTG & 0 & 0 & & & & \\
\hline & \multirow[t]{2}{*}{ CTT } & \multirow[t]{2}{*}{13} & \multirow[t]{2}{*}{35} & \multirow{2}{*}{$\begin{array}{l}\text { Cys } \\
(?)\end{array}$} & TGC & 2 & 0 \\
\hline & & & & & TGT & 34 & 25 \\
\hline \multirow{3}{*}{$\begin{array}{l}\text { Leu } \\
\text { (uaa) }\end{array}$} & TTA & 488 & 472 & & & & \\
\hline & \multirow[t]{2}{*}{ TTG } & \multirow[t]{2}{*}{15} & \multirow[t]{2}{*}{24} & \multirow{2}{*}{$\begin{array}{l}\text { Met } \\
\text { (cau) }\end{array}$} & ATA & 386 & 312 \\
\hline & & & & & ATG & 14 & 22 \\
\hline \multirow{4}{*}{$\begin{array}{l}\text { Pro } \\
\text { (ugg) }\end{array}$} & CCA & 61 & 64 & & & & \\
\hline & $\mathrm{CCC}$ & 2 & 3 & \multirow{2}{*}{$\begin{array}{l}\text { Tyr } \\
\text { (gua) }\end{array}$} & TAC & 5 & 10 \\
\hline & $\mathrm{CCG}$ & 0 & 0 & & TAT & 233 & 209 \\
\hline & CCT & 33 & 36 & & & & \\
\hline \multirow{5}{*}{$\begin{array}{l}\text { Ala } \\
\text { (ugc) }\end{array}$} & & & & \multirow{3}{*}{$\begin{array}{l}\text { Phe } \\
\text { (gaa) }\end{array}$} & TTC & 17 & 26 \\
\hline & GCA & 28 & 36 & & TTT & 423 & 354 \\
\hline & GCC & 1 & 1 & & & & \\
\hline & GCG & 0 & 0 & \multirow{2}{*}{$\begin{array}{l}\text { Gln } \\
(?)\end{array}$} & CAA & 38 & 39 \\
\hline & GCT & 12 & 20 & & $\mathrm{CAG}$ & 1 & 2 \\
\hline \multirow{5}{*}{$\begin{array}{l}\text { Arg } \\
\text { (ucg) }\end{array}$} & CGA & 28 & 29 & \multirow{3}{*}{$\begin{array}{l}\text { Glu } \\
\text { (uuc) }\end{array}$} & GAA & 65 & 74 \\
\hline & CGC & 0 & 0 & & GAG & 3 & 5 \\
\hline & CGG & 1 & 1 & & & & \\
\hline & CGT & 8 & 9 & His & CAC & 0 & 3 \\
\hline & & & & (gug) & CAT & 56 & 57 \\
\hline \multirow{4}{*}{$\begin{array}{l}\text { Val } \\
\text { (uac) }\end{array}$} & GTA & 31 & 53 & & & & \\
\hline & GTC & 0 & 1 & \multirow{3}{*}{$\begin{array}{l}\text { Ile } \\
(?)\end{array}$} & ATC & 21 & 26 \\
\hline & GTG & 0 & 0 & & ATT & 477 & 476 \\
\hline & GTT & 38 & 67 & & & & \\
\hline \multirow{3}{*}{$\begin{array}{l}\text { Asn } \\
\text { (guu) }\end{array}$} & & & & Lys & $\mathrm{AAA}$ & 174 & 152 \\
\hline & $\mathrm{AAC}$ & 17 & 11 & & $\mathrm{AAG}$ & 1 & 8 \\
\hline & AAT & 265 & 238 & & & & \\
\hline Trp & TGA & 71 & 78 & & & & \\
\hline (uca) & TGG & 1 & 5 & & & & \\
\hline
\end{tabular}

mellifera 16S gene (Crozier and Crozier, 1993), and their nucleotide similarity was $81 \%$. The $16 \mathrm{~S} \mathrm{G}+\mathrm{C}$ content in $M$. bicolor is $13.2 \%$, while A. mellifera is $15.4 \%$ and Drosophila yakuba, 17\%.

The sequence for the small rRNA subunit (srRNA or $12 \mathrm{~S}$ ) was not obtained completely because it flanks the control region of the mtDNA, which was not amplified. Assuming that this gene has the same length as A. mellifera, we sequenced $55 \%$ of it ( $437 \mathrm{bp}$ ). The sequence similarity between $A$. mellifera and $M$. bicolor for this sequenced fragment is $79 \%$. As found for $16 \mathrm{~S}$, the $12 \mathrm{~S}$ sequenced stretch presented a higher $\mathrm{A}+\mathrm{T}$ content ( $83 \%$ ) comparing to A. mellifera (81\%) and D. yakuba $(79 \%)$.

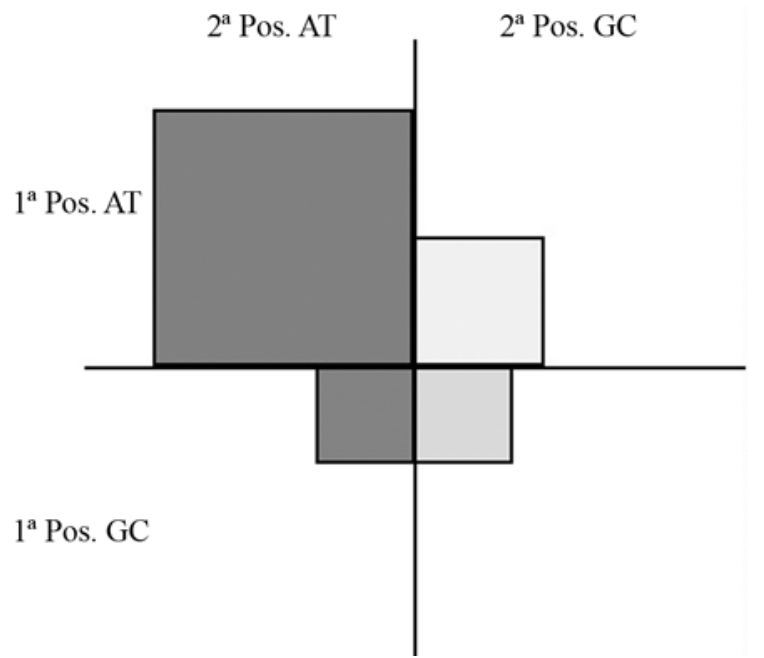

Figure 2 - Square plot of M. bicolor mtDNA. Each quadrant is proportionally dimensioned to the number of codons that are composed by AT or GC on first position (vertical axis) and on second position (horizontal axis).

Table 6 - Comparisons of protein-coding genes between M. bicolor (Mbi) and A. mellifera (Ame). Lengths are expressed in basepairs (bp). Start: Start codon; Stop: Stop codon; and Nuc Sim: raw nucleotide similarity between the two bee species. Different start or stop codons are indicated in italic.

\begin{tabular}{lrrlllll}
\hline Gene & $\begin{array}{c}\text { Length } \\
\text { Mbi }\end{array}$ & $\begin{array}{c}\text { Length } \\
\text { Ame }\end{array}$ & $\begin{array}{c}\text { Start } \\
\text { Mbi }\end{array}$ & $\begin{array}{c}\text { Start } \\
\text { Ame }\end{array}$ & $\begin{array}{c}\text { Stop } \\
\text { Mbi }\end{array}$ & $\begin{array}{c}\text { Stop } \\
\text { Ame }\end{array}$ & $\begin{array}{c}\text { Nuc } \\
\text { Sim }\end{array}$ \\
\hline ATP6 & 684 & 681 & ATG & ATG & TAA & TAA & $79 \%$ \\
ATP8 & 168 & 159 & ATT & ATT & TAA & TAA & $72 \%$ \\
COI & 1560 & 1566 & $A T T$ & $A T A$ & TAA & TAA & $86 \%$ \\
COII & 678 & 676 & ATT & ATT & TAA & $T$ & $82 \%$ \\
COII & 780 & 777 & ATG & ATG & TAA & TAA & $77 \%$ \\
CytB & 1050 & 1152 & ATT & ATG & TAA & TAA & $80 \%$ \\
ND1 & 930 & 918 & ATA & $A T T$ & TAA & TAA & $75 \%$ \\
ND2 & 939 & 1002 & ATA & $A T C$ & TAA & TAA & $69 \%$ \\
ND3 & 354 & 354 & ATA & ATA & TAA & TAA & $73 \%$ \\
ND4 & 1323 & 1344 & ATT & $A T A$ & TAA & TAA & $76 \%$ \\
ND4L & 279 & 264 & $A T A$ & $A T T$ & TAA & TAA & $72 \%$ \\
ND5 & 1647 & 1665 & ATT & ATT & TAA & TAA & $77 \%$ \\
ND6 & 540 & 504 & ATT & ATT & TAA & TAA & $69 \%$ \\
\hline
\end{tabular}



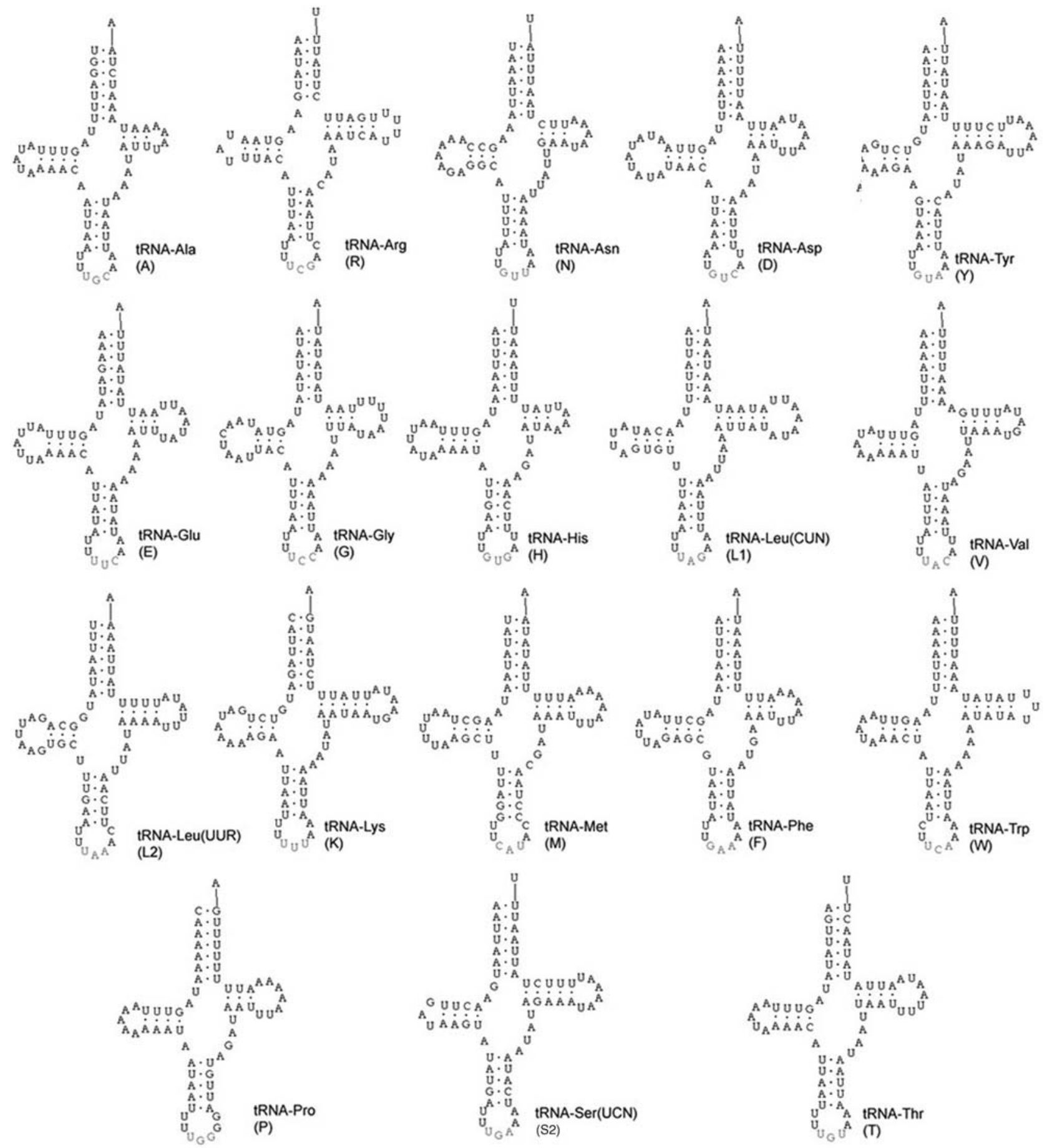

Figure 3 - Schematic representation of the tRNA secondary structures predicted from the Melipona bicolor genome. The anticodon triplet is represented in gray.

The difference in size observed for the $16 \mathrm{~S}$ gene is quite small, since we have found variations of $102 \mathrm{bp}$ for protein-coding genes (cytB). Size differences are acceptable on rRNA genes more than on protein-coding genes, since there is no need to maintain a frame to read, and only the secondary structure matters to their function (Wolstenholme, 1992). Castro and Dowton (2005) aligned the $12 \mathrm{~S}$ and $16 \mathrm{~S}$ genes of several insects and found con- served sequence blocks, indicating that the rRNA secondary structure is also conserved as consequence.

\section{Difficulties to amplify the A+T-rich region in $M$. bicolor}

The A+T-rich region appears generally difficult to amplify in insects, mainly due to tandem repeats, heteroplasmy and great length variation at intra and inter-specific 
levels (Zhang and Hewitt, 1997). Also the use of heterospecific primers, designed from flanking tRNA gene sequences, may lead to amplification failure if one of those genes is translocated to another region of the genome (Zhang and Hewitt, 1997).

Our inability to amplify the control region of $M$. bicolor may also be explained by its size. Weinlich et al. (2004) estimated it to be about 3,300 bp long, around $2.5 \mathrm{~kb}$ longer than in A. mellifera (Crozier and Crozier, 1993). Normally such differences are due to partial duplications inside this region, a common feature of insect mtDNA ( $\mathrm{Si}$ mon et al., 1994), which may also make amplification difficult.

\section{Transfer RNA genes}

The tRNA genes were mainly identified by eye, using simple local alignment with their homologues in $A$. mellifera mtDNA. However, when detection was difficult due to low similarity or translocations, these regions were analyzed with specific software (tRNA-Scan, Lowe and Eddy, 1997), which identifies the genes and folds them in typical cloverleaf structures.

From the 22-23 tRNA genes regularly found in animal mitochondrial genomes, 19 were identified on $M$. bicolor mtDNA (Figure 3). The four missing genes were tRNAs for Cys, Gln, Ile and Ser (S1). Although the tRNA ${ }^{\text {Ile }}$ gene could be identified and positioned on the M. bicolor genome, its sequence was not entirely obtained. Analyzing all the $M$. bicolor tRNA sequences as a whole, we have 1,193 bp, with $11.1 \% \mathrm{G}+\mathrm{C}$ and $88.9 \% \mathrm{~A}+\mathrm{T}$. The proportion of $\mathrm{A}+\mathrm{T}$ for the same genes of $A$. mellifera is slightly less: $87.1 \%$.

The secondary structures of tRNAs of A. mellifera and $M$. bicolor were very similar. Nonetheless, a few differences were found, concentrated at the $\mathrm{D}$ and $\mathrm{T} \Psi \mathrm{C}$ arms, considered the most variable ones (Clary and Wolstenholme, 1985). The anticodon loop always had seven nucleotides, and its arm always had five base pairs, except on A. mellifera tRNA $^{\text {Val }}$ (4 bp). The acceptor arm was also conserved in size (7 bp), except on M. bicolor tRNA ${ }^{\mathrm{Arg}}(6 \mathrm{bp})$. The anticodons were the same for both species.

Eleven tRNA gene clusters (Figure 1) were identified, comprising the 19 tRNA genes sequenced. Nine tRNA genes of $M$. bicolor are on different positions or strands when compared with A. mellifera. Two tRNA genes had their position inferred based on their absence in the predicted or sequenced locations. These 11 genes are distributed in only 4 clusters. This number of translocations is higher than those usually found between pairs of Diptera species (OGRE). The molecular and evolutionary implications of this phenomenon on bees are discussed elsewhere (Silvestre et al., 2002; Silvestre and Arias, 2006).

\section{The KD tRNA cluster in Meliponini}

In insects, the junction between the cytochrome oxidase II and ATPase 8 genes normally contains two
tRNA genes, tRNA ${ }^{\text {Lys }}(\mathrm{K})$ and tRNA ${ }^{\text {Asp }}$ (D) (e.g. Clary and Wolstenholme, 1985). This junction has been called the KD cluster (Dowton and Austin, 1999), as the plesiomorphic organization is considered to be KD (i.e. COIIK-D-ATP8); this arrangement has been verified in several members of the Hymenoptera, Diptera and Orthoptera. However, in $M$. bicolor this cluster is represented only by the tRNA $^{\text {Asp }}$ (D) gene, while A. mellifera has the plesiomorphic organization (KD). This observation led us to amplify, sequence and characterize the KD cluster in 14 Meliponini species, representing the large distributional range of the tribe. Species from Brazil, India, Thailand, Australia and Africa were analyzed; all contained only the tRNA $^{\text {Asp }}$ gene (D). In the M. bicolor mitochondrial genome, the tRNA ${ }^{\text {Lys }}$ gene is located in the first tRNA cluster, near the $\mathrm{A}+\mathrm{T}$ rich region; this region is considered a hot spot of translocation events (Boore and Brown, 1998). Although we have not sequenced cluster one in the additional meliponine species (to confirm the location of the tRNA ${ }^{\text {Lys }}$ gene), its absence in the KD cluster is a strong argument that the translocation of this gene occurred very early in the evolutionary history of Meliponini, and seems to be a fixed character of the tribe. Data from other bee families and tribes were obtained (Dowton and Austin, 1999; Silvestre and Arias, unpublished data) and reinforce that this gene rearrangement is a unique feature of Meliponini.

The mitochondrial genome of M. bicolor is the first that has been sequenced for stingless bee species. This work provides critical data for future mtDNA analyses of other meliponine species, facilitating the investigation of biological, ecological and evolutionary questions at intraand inter-specific levels. As several stingless bees are considered endangered, population studies applying molecular tools will be very important in terms of conservation. The sequence obtained here, representing $78 \%$ of the total genome, has been available in GenBank since 2003, and has already been used for phylogenetic purposes (Castro and Dowton, 2005) in an attempt to reconstruct the phylogeny of the Holometabola and the position of the Hymenoptera within it. There is an emerging tendency to use complete or nearly complete mtDNA genome sequences for phylogenetic analysis, while this type of data may also provide gene order characters for phylogenetic inferences (Boore and Brown, 1998; Rawlings et al., 2001). It is worthwhile to note the high rate of tRNA gene rearrangement found in the M. bicolor mitochondrial genome in comparison to other insects. Studies on wasps have already indicated that the Hymenoptera generally have an accelerated rate of mtDNA gene rearrangement (Dowton and Austin, 1999; Dowton et al, 2002; Dowton et al., 2003). Gene order characters may help resolve the evolution and phylogeny of the bees, particularly the unsolved question about the origin of eusociality among corbiculate bees. The high conservation of the translocation of the tRNA ${ }^{\text {Lys }}$ gene in Meliponini suggests that it occurred before the great diversification of 
Meliponini species and their dispersion over the tropical and southern subtropical areas of the World. The inclusion of more molecular data and analysis of other tRNA clusters may provide further clues for the evolution and biogeography of the Meliponini.

\section{Acknowledgments}

Thanks are due to Peter Kwapong, Connal Eardley and Isabel Alves dos Santos for providing specimens from Africa and Thailand. Thanks also to Patricia Drumond, Richard Rowe and Ross Crozier for provision of specimens from Australia. We are grateful to Susy Coelho, Cristina Costa and Ivone Fonseca for their technical assistance, and Dr. Walter Steven Sheppard for his careful reading of the manuscript and suggestions. This work was supported by 'Fundação de Amparo à Pesquisa do Estado de São Paulo' (Fapesp - 99/10969-0).

\section{References}

Arias MC, Brito RM, Francisco FO, Moretto G, de Oliveira FF, Silvestre D and Sheppard WS (2006) Molecular markers as a tool for population and evolutionary studies of stingless bees. Apidologie 37:259-274.

Arias MC, Silvestre D, Francisco FO, Weinlich R and Sheppard WS (2008) An oligonucleotide primer set for PCR amplification of the complete honey bee mitochondrial genome. Apidologie 39, in press.

Beagley CT, Okimoto R and Wolstenholme DR (1998) The mitochondrial genome of the sea anemone Metridium senile (Cnidaria): Introns, a paucity of tRNA genes, and a nearstandard genetic code. Genetics 148:1091-1108.

Boore J (1999) Animal mitochondrial genomes. Nucleic Acids Res 27:1767-1780.

Boore JL (2001) Complete mitochondrial genome sequence of the polychaete annelid Platynereis dumerilii. Mol Biol Evol 18:1413-1416.

Boore JL and Brown WM (1998) Big trees from little genomes: Mitochondrial gene order as a phylogenetic tool. Curr Opin Genet Dev 8:668-674.

Boore JL, Collins TM, Stanton D, Daehler LL and Brown WM (1995) Deducing the pattern of arthropod phylogeny from mitochondrial DNA rearrangements. Nature 376:163-165.

Brito RM and Arias MC (2005) Mitochondrial DNA characterization of two Partamona species (Hymenoptera, Apidae, Meliponini) by PCR-RFLP and sequencing. Apidologie 36:431-437.

Brown WM (1985) The mitochondrial genome of animals. In: MacIntyre RJ (ed) Molecular Evolutionary Genetics. Plenus Press, New York, pp 95-130.

Castro LR and Dowton M (2005) The position of the Hymenoptera within the Holometabola as inferred from the mitochondrial genome of Perga condei (Hymenoptera, Symphyta, Pergidae). Mol Phylogenet Evol 34:469-479.

Castro LR, Austin AD and Dowton M (2002) Contrasting rates of mitochondrial molecular evolution in parasitic Diptera and Hymenoptera. Mol Biol Evol 19:1100-1113.
Clary DO and Wolstenholme DR (1985) The mitochondrial DNA molecule of Drosophila yakuba: Nucleotide sequence, gene organization, and genetic code. J Mol Evol 22:252-271.

Cornuet JM, Garnery L and Solignac M (1991) Putative origin and function of the intergenic region between $\mathrm{COI}$ and $\mathrm{COII}$ of Apis mellifera L. mitochondrial DNA. Genetics 1128:393-403.

Crozier RH and Crozier YC (1993) The mitochondrial genome of the honeybee Apis mellifera: Complete sequence and the genome organization. Genetics 133:97-117.

Dowton M and Austin AD (1999) Evolutionary dynamics of a mitochondrial rearrangement "hot spot" in the Hymenoptera. Mol Biol Evol 16:298-309.

Dowton M and Campbell NJH (2001) Intramitochondrial recombination: Is it why some mitochondrial genes sleep around? Trends Ecol Evol 16:269-271.

Dowton M, Belshaw R, Austin AD and Quicke DL (2002) Simultaneous molecular and morphological analysis of Braconid relationships (Insecta, Hymenoptera, Braconidae) indicates independent mt-tRNA gene inversions within a single wasp family. J Mol Evol 54:210-226.

Dowton M, Castro LR, Campbell SL, Bargon SD and Austin AD (2003) Frequent mitochondrial gene rearrangements at the hymenopteran nad3-nad5 junction. J Mol Evol 56:517-526.

Foster PG, Jermiin LS and Hickey DA (1997) Nucleotide composition bias affects amino acid content in proteins coded by animal mitochondria. J Mol Evol 44:282-288.

Francisco FO, Silvestre D and Arias MC (2001) Mitochondrial DNA characterization of five species of Plebeia (Apidae, Meliponini): RFLP and restriction maps. Apidologie 32:323-332.

Franck P, Garnery L, Solignac M and Cornuet J-M (1998) The origin of west European subspecies of honeybees (Apis mellifera) new insights from microsatellite and mitochondrial data. Evolution 52:1119-1134.

Garnery L, Cornuet J-M and Solignac M (1992) Evolutionary history of the honey bee Apis mellifera inferred from mitochondrial DNA analysis. Mol Ecol 1:145-154.

Garnery L, Mosshine EH, Oldroyd BP and Cornuet J-M (1995) Mitochondrial DNA variation in Moroccan and Spanish honey bee populations. Mol Ecol 4:465-471.

Hall HG and Smith DR (1991) Distinguishing African and European honeybee matrilines using amplified mitochondrial DNA. Proc Natl Acad Sci USA 88:4248-4552.

Hoffmann RJ, Boore JL and Brown WM (1992) A novel mitochondrial genome organization for the blue mussel, Mytilus edulis. Genetics 131:397-412.

Jameson D, Gibson AP, Hudelot C and Higgs PG (2003) OGRe: a relational database for comparative analysis of mitochondrial genomes. Nucleic Acids Res 31:202-206.

Kerr WE, Carvalho GA and Nascimento VA (1996) Abelha Uruçu-Biologia, Manejo e Conservação. Fundação Acangaú, Belo Horizonte, 143 pp.

Lowe TM and Eddy SR (1997) tRNAscan-SE: A program for improved detection of transfer RNA genes in genomic sequence. Nucleic Acids Res 25:955-964.

Michener CD (2000) The Bees of the World. The Johns Hopkins University Press, Baltimore, 952 pp.

Mindell DP, Sorenson MD and Dimcheff DE (1998) Multiple independent origins of mitochondrial gene order in birds. Proc Natl Acad Sci USA 95:10693-10697. 
Nogueira-Neto P (1997) Vida e Criação de Abelhas Indígenas sem Ferrão. Nogueirapis, São Paulo, 446 pp.

Okimoto R, Macfarlane JL, Clary DO and Wolstenholme DR (1992) The mitochondrial genome of two nematodes, Caenorhabditis elegans and Ascaris suum. Genetics 130:471-498.

Pesole G, Attimonelli M and Liuni S (1988) A backtranslation method based on codon usage strategy. Nucleic Acids Res 5:1715-1728.

Rawlings TA, Collins TM and Bieler R (2001) A major mitochondrial gene rearrangement among closely related species. Mol Biol Evol 18:1604-1609.

Shao R, Dowton M, Murrell A and Barker SC (2003) Rates of gene rearrangement and nucleotide substitution are correlated in the mitochondrial genomes of insects. Mol Biol Evol 20:1612-1619.

Sheppard WS and McPheron B (1991) Ribosomal DNA diversity in Apidae. In: Smith DR (ed) Diversity in the Genus Apis. Westview Press, Boulder, pp 89-102.

Silvestre D and Arias MC (2006) Mitochondrial tRNA gene translocations in highly eusocial bees. Genet Mol Biol 29:572-575.

Silvestre D, Francisco FO, Weinlich R and Arias MC (2002) A scientific note on mtDNA gene order rearrangements among highly eusocial bees. Apidologie 33:355-356.

Simon C, Frati F, Beckenbach A, Crespi B, Liu H and Flook P (1994) Evolution, weighting, and phylogenetic utility of mitochondrial gene sequences and a compilation of conserved polymerase chain reaction primers. Ann Entomol Soc Am 87:651-701.

Velthuis HHW, De Vries H and Imperatriz-Fonseca VL (2006) The polygyny of Melipona bicolor: Scramble competition among queens. Apidologie 37:222-239.

Weinlich R, Francisco FO and Arias MC (2004) Mitochondrial DNA restriction and genomic maps of seven species of Melipona (Apidae, Meliponini). Apidologie 35:365-370.

Wolstenholme DR (1992) Animal mitochondrial DNA: Structure and evolution. Int Rev Cytol 141:173-216.

Xia X (1996) Maximizing transcription efficiency causes codon usage bias. Genetics 144:1309-1320.

Xia X (2000) Data analysis in molecular biology and evolution. Kluwer Academic Publishers, Boston/Dordrecht/London, 296 pp.

Zhang D and Hewitt GM (1997) Insect mitochondrial control region: A review of its structure, evolution and usefulness in evolutionary studies. Biochem System Ecol 25:99-120.

\section{Internet Resources}

National Center for Biotechnology Information (NCBI), BLAST searches, http://www.ncbi.nlm.nih.gov/BLAST.

TraceViewer 2.0.1, http://www.codoncode.com. tRNA-Scan, http://lowelab.ucsc.edu/tRNAscan-SE/.

\section{Assistant Editor: Klaus Hartfelder}

License information: This is an open-access article distributed under the terms of the Creative Commons Attribution License, which permits unrestricted use, distribution, and reproduction in any medium, provided the original work is properly cited. 